\title{
Collaborative or adversarial production and BIM: a method for better understanding of contracting types, based on BPMN
}

\section{SIGRADI2018 TECHNOPOLITICAS \\ xxii congresso da sociedade iberoamericana de gráfica digital 22th conference of the iberoamerican society of digital graphics 07|08|09|novembro|2018 iau usp | são carlos | sp br}

\author{
Ana Beatriz de Figueiredo Oliveira \\ School of Architecture and Urbanism - University of São Paulo | Brazil | anabeatrizfig@usp.br \\ Marcelo Eduardo Giacaglia \\ School of Architecture and Urbanism - University of São Paulo | Brazil | mgiacagl@usp.br
}

\begin{abstract}
BIM represents a paradigm change in the production process, and its use can be facilitated or hindered by the contracting scheme. Contracting can be relational or transactional; the first refers to collaboration and the second to an adversarial environment. In literature, the different contracting schemes are presented in textual form, which is not the best format to analyze similarities and differences among them. A graphical form for comparison is proposed, using the well-known diagrams of AIA and the BPMN notation. A collaborative production process favors integration and the use of BIM, resulting in more efficiency and quality of the project.
\end{abstract}

Keywords BIM; BPMN; Construction contract; Integration; Production process.

\section{INTRODUCTION}

Integration of the production process is argued to be the solution for a wide range of issues in construction, for instance, lack of collaboration, low effectiveness of production process, and unsatisfactory quality of construction (Egan, 2002; American Institute of Architects, 2014; El Asmar; Hanna; Loh, 2015).

The concept of integration is present for quite some time in the construction industry. Nam and Tatum (1992) defined integration as a great opportunity to increase the rate of innovation on construction projects. These authors also listed three approaches for integration: organizational, contractual, and information processing technology.

BIM is one of the information processing technology approaches towards integration since it represents a paradigm change in the production process. Eastman et al. (2011) indicate that BIM breaks with the linear process of exchange of information, which works with paper-based models of communication. The virtual models have precise information to support the construction, fabrication, and procurement activities.

According to Miettinen and Paavola (2014) BIM is frequently related to a tool of collaboration, which can reduce design mistakes and increases the productivity of the construction industry. However, these authors observed that the increase of BIM use did not cause a qualitative change to the fragmentation of the production process. Thus, it is also necessary to change organizational and legal issues to achieve integration of the whole process.

According to Eastman et al. (2011), the use of BIM can be facilitated or hindered by the contracting scheme. The whole positive changes influenced by BIM cannot be achieved if the project delivery method does not have the features to support it. More information about contracting can result in a more adequate decision of which project delivery method should be used in each construction process.

Different contracting types have been described in literature, usually in textual form (Eastman, et al., 2011; Scheepbouwer; Humphries, 2011; Lahdenperä, 2012; El Asmar; Hanna; Loh, 2015). Comparisons between them are difficult if based solely on textual descriptions.

The well-known diagrams produced by the American Institute of Architects (AIA) (2014), is a special case in the literature. However, they are presented as either the traditional or the integrated types. Between these two, there are several possibilities.

In this research, a graphical method to better understand the most important features of any contracting scheme, and to enable comparison among different schemes is proposed.

\section{METHODOLOGY}

The features of AIA's diagram are useful as stereotypes, and cannot show differences among actual contracting schemes, especially those belonging to the same category. It was proposed that the general AIA's diagrams be augmented to show the necessary details, regarding exchange of contracts and related communication among agents. It was proposed that such detailing can be done through the use of BPMN notation which is a wellestablished notation to describe workflows (Object Management Group, 2011) (Figure 1). 


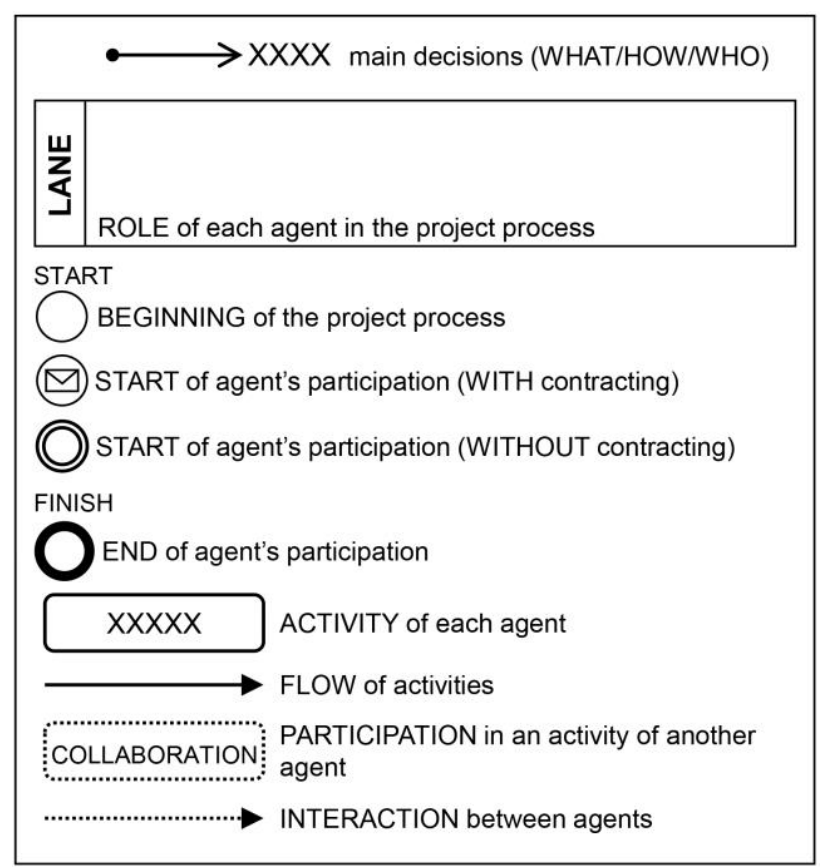

Figure 1: Elements of the BPMN diagrams. Adapted from Object Management Group (2011).

The features of the AIA diagrams were kept, especially the stages of the production process and the main decisions what, how, and who. What represents all the characteristics of the building, considering design, structure, and all functional aspects, such as the facilities. The procedures selected to construct the building is represented by how, and the selection of the agents responsible for the construction is indicated by who.

The diagrams were augmented with a lane for each main participant - owner, designer, contractor, subcontractor, and agency -, indicating the activities that each one is responsible for; the collaboration between disciplines; the interactions between the activities; and the moment that each participant starts and finishes its involvement in the process.

A second set of diagrams were developed to summarize the interaction among the key stakeholders in each contracting scheme - owner, designer, contractor, and subcontractor - and the type of interactions that occur contract, delivery and collaboration (Figure 2). BIM requires collaboration throughout the production process. The more isolated the participants, more difficult to achieve the full benefit from BIM.

\section{KEY PARTICIPANTS:}

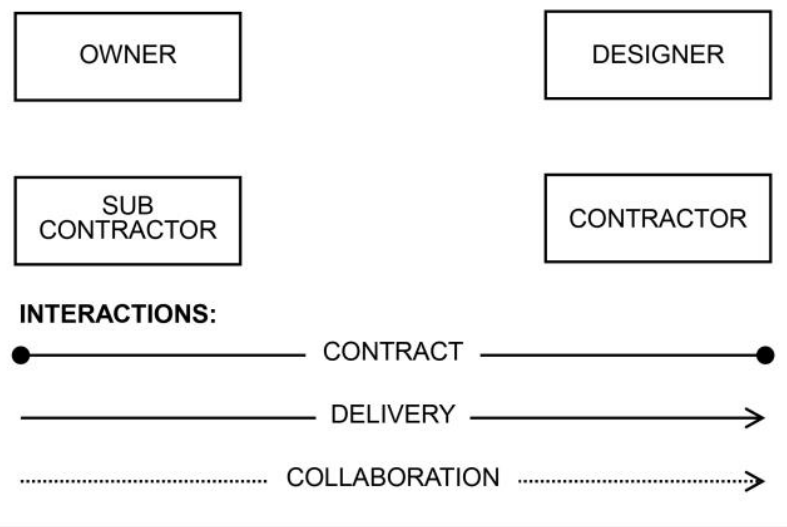

Figure 2: Elements of the summary of interactions diagrams.

\section{CONTRACTING TYPES}

The project delivery method is the complete process by which designers, contractors, subcontractors, and various consultants provide design and construction services to deliver a complete project to the owner (Molenaar; Sobin, 2009). Contracts organize and establish how the project delivery method needs to be conducted.

Mosey (2009) defines contract as the agreement between two or more parts, which has three essential purposes: define rights, responsibilities, and procedures; identify and allocate risks; and define the planning of the production process.

There are different types of contracts, which vary according to some instruments, such as the agents' participation through the production process, interactions between parties, and number of agreements with the owner.

One possible categorization for contracting systems is based on the focus of the clauses. Transactional contracting focuses on the deliverables and, consequently, it specifies each agent's responsibilities. Relational contracting focuses on the interactions among the agents throughout the whole process, and collaboration is a requisite for production (Matthews; Howell, 2005).

Literature identifies these common contracting types (Eastman, et al., 2011; Scheepbouwer; Humphries, 2011; Lahdenperä, 2012; El Asmar; Hanna; Loh, 2015): DesignBid-Build (DBB), Design and Build (DB), and Construction Management at Risk (CMAR), in the transactional category; and Project Partnering (PP), Project Alliancing (PA), Early Contractor Involvement (ECI), and Integrated Project Delivery (IPD), in the relational category.

\section{TRANSACTIONAL CONTRACTS}

Transactional contracts are based on the exchange of goods and services. The focus of the clauses is on describing in detail the service that will be provided, as the design and construction. In these types of contracts, there are many clauses related to the penalties which can be applied if the participants do not deliver the services with the expected quality (Rahman; Kumaraswamy, 2005).

The main advantage of this category of contracting is its widespread use within the construction industry, which 
makes it easily understandable by the participants. On the other hand, the detailed information about the object obligates the development of most part of the design before contracting all the participants, which could hinder the collaboration between agents.

In DBB the design and construction activities are dissociated, since the production process is divided into three essential and independent stages: design, bid and build. DB brings together the designer and the contractor into a single agent that establishes one contract with the owner, in order to simplify the process. CMAR adds a new competency to the process - the construction manager -, which is responsible for the construction and the management of the whole project (Construction Management Association of America, 2012).

\section{RELATIONAL CONTRACTS}

Relational contracting is structured upon the relationship between the participants in order to create a work environment based on trust and collaboration. The clauses indicate the obligation of transparency of information exchange and establish how the conflicts between agents can be settled, to avoid disputes and claims (Harper; Molenaar; Cannon, 2016).

The main advantage of relational contracting is to encourage collaboration between the parties, in that all agents work towards a common goal, rather than focusing only on the activity of his responsibility. The less use of relational contracting in construction market could be a disadvantage, since owners and professionals might find it difficult and not so confident to establish these types of contract. As the object is not clearly defined, the participants might consider these contracts vague, which might increase the risk of the project.

A multi-party contract is often used in relational contracting. This instrument creates a temporary organization formed by the agents, and there is only one agreement between the owner and the key participants (Lahdenperä, 2012).

PP was developed as a management instrument that improves the production process by removing the barriers between the participants. PA is a project delivery method most used in Australia, and it arranges the parties similarly to a business organization (Lahdenperä, 2012). ECI has a unique feature, the division of the contracting process into at least two stages - concept design, and design/construction (Scheepbouwer; Humphries, 2011). IPD is the newest of these methods and it includes the agency responsible for the design approval from the beginning of the process (American Institute of Architects, 2014).

\section{RESULTS}

The diagrams represent each contracting type through the proposed notation. A common organization for the columns representing the main stages of the process: concept, design and construction, and the placement of the main participants: owner, designer, contractor, subcontractor and agency, in the same lanes, favors comparisons among the schemes.

\section{DESIGN-BID-BUILD (DBB)}

The complete division of activities can be observed on the diagram for DBB (Figure 3). The main decisions - what, how, and who - are made extremely late in the production process. Each agent participates only in the activity that he/she was designated for and the owner is the agent responsible for the continuity of the process (Figure 4).

Whenever a new participant starts his involvement in the project possible issues are detected leading to delays and/or rework. This could increase the cost and schedule planned and compromise the quality of the building. DBB has three potential occurrences for rework, especially due to the separation between design and construction stages.

BIM requires that the virtual model represents precisely the real building, which indicates the necessity to consider the construction phase in the concept and design phases. The lack of integration between the DBB production process hampers the use of BIM. Each time a new participant starts to work on the production process, a new analysis of the virtual model or a new modeling activity is required.

\section{DESIGN AND BUILD (DB)}

In DB (Figure 5) the owner establishes only one contract, with the association of the designer and the contractor, for the entire project, which results in the collaboration between these two disciplines - design and construction (Figure 6).

The early involvement of the contractor allows the anticipation of the beginning of the decisions of how the project will be built and who will build it. Earlier the decisions are made, more opportunities are created to enhance the whole benefits of BIM.

However, the later involvement of the subcontractor and the participation of the agency only on the design stage results in two potential occurrences for rework that could demand changes to the concept stage of the project. When modifications are made later in the process, more difficult are the solutions, because of the progressive delays and costs.

\section{CONSTRUCTION MANAGEMENT AT RISCK (CMAR)}

In CMAR, the owner signs two separate contracts with the designer and the contractor, who is also the general manager of the project (Figure 7 and 8). The contractor participates at the beginning of the process, concurrently with the designer, resulting in collaboration between these professionals.

The potential occurrences for rework and the opportunities of the use of BIM on CMAR are similar to DB, because of the late involvement of the agency and the subcontractor. Even with the presence of a general manager throughout the process, a new agent starting to participate in the middle of the process could demand changes to the project.
3 


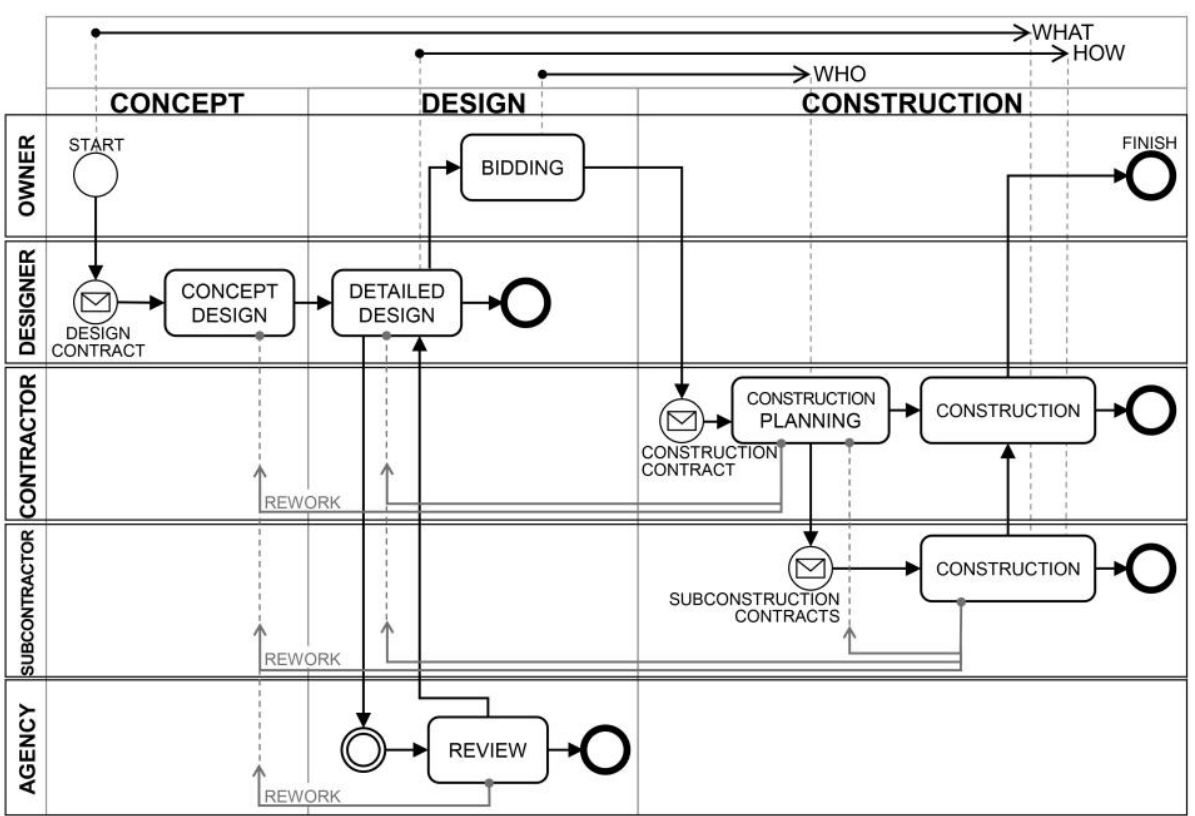

Figure 3: Diagram for Design-Bid-Build (DBB).

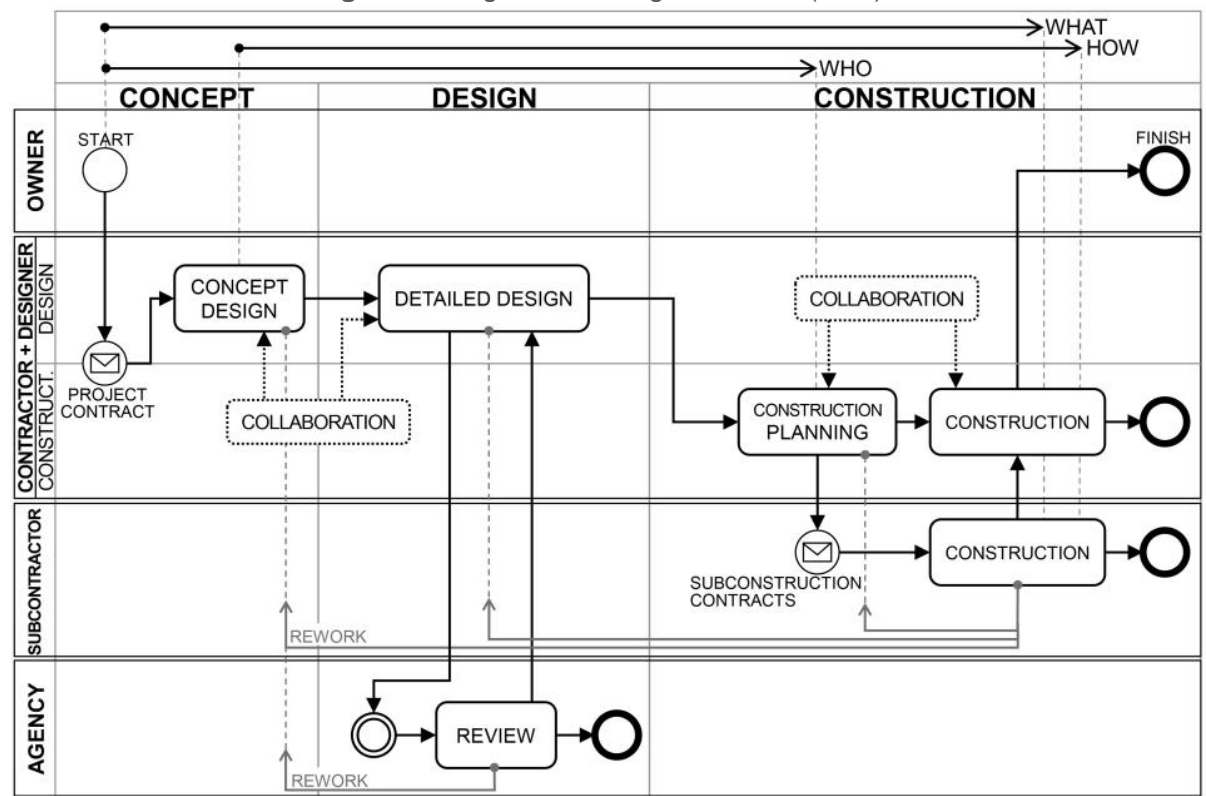

Figure 5: Diagram for Design and Build (DB).

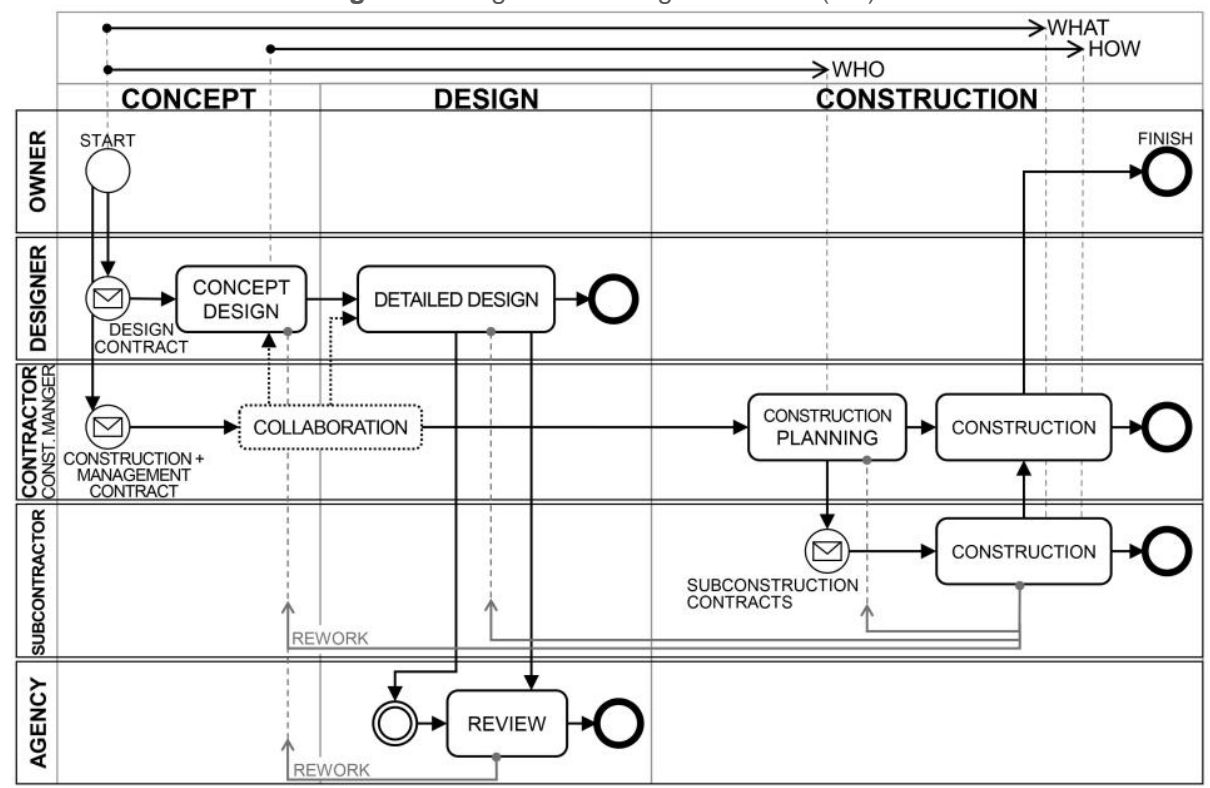

Figure 7: Diagram for Construction Management at Risk (CMAR).

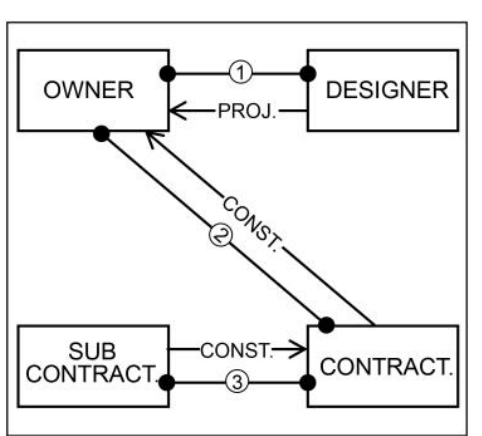

Figure 4: Interactions in DBB.

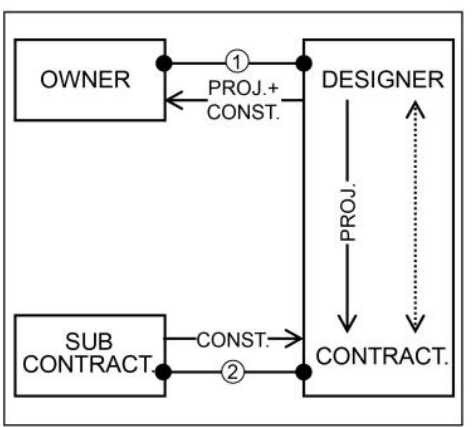

Figure 6: Interactions in DB.

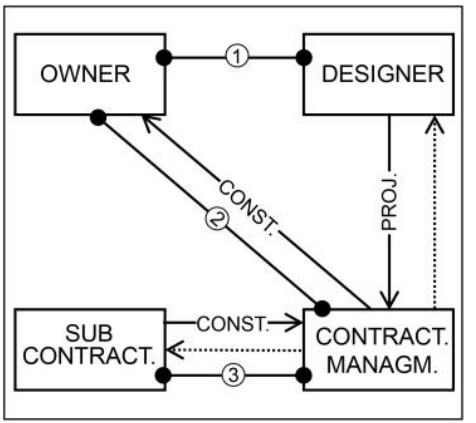

Figure 8: Interactions in CMAR. 


\section{PROJECT PARTNERING (PP) AND PROJECT ALLIANCING (PA)}

The same diagram illustrates PP and PA (Figure 9), since the differences between these two are related to some clauses that do not have an impact on the workflows, such as the payment agreement and the resolution of claims.

The early involvement of all agents allows the conclusion of the main decisions before the construction stage. As a result, the construction activity does not include reviews on the detailed design. The presence of collaboration throughout the process facilitates the use of BIM, creating an environment with great opportunities to achieve all benefits of BIM.

Even though, the presence of the agency only on the design stage creates a possibility for rework that can change some aspects of the project on the concept stage.

\section{EARLY CONTRACTOR INVOLVEMENT (ECI)}

In figure 10, it is possible to observe that in $\mathrm{ECl}$ the division of the process into two stages affects how the collaboration will occur. Even though the owner maintains a multi-party agreement with the key participants, the collaboration does not start at the concept stage. As a result, ECI has two potential occurrences for rework: when the subcontractor starts his involvement and to obtain the approval of the project by the agency.

\section{INTEGRATED PROJECT DELIVERY (IPD)}

IPD's distinguishing feature is the early participation of the approval agency in the process (Figure 11). It is a collaborator even though its participation is not based on a contract. The inclusion of the agency on the concept stage minimizes the possibility of any rework related to the late involvement of a participant.

IPD can provide the best opportunity to achieve the whole benefits of BIM. Earlier the decisions are made in the process, more accurate information of the building will be incorporated into the virtual model, which integrates the whole process.

The summaries for PP, PA, ECI and IPD are the same, as are the relations among key participants. Figure 12 depicts a collaboration environment that greatly favors BIM.

\section{DISCUSSION}

Different aspects of contracting produce impacts on the manner that a production process is settled. Those impacts influence the use of BIM, facilitating or hindering its insertion on the process.

With the diagrams proposed, it was possible to identify differences and similarities among each contracting type, and the features that can undermine or potentiate the use of BIM.

It was identified that the early involvement of the participants can improve integration of the process and facilitates the use of BIM. The early involvement of all participants reduces the possibility of rework in the construction process. As soon as the agents are aware of the design, and have already included their considerations to the project, less or no changes are necessary to be done in the construction stage.

The earlier the building aspects are defined, the more accurate is the virtual model. Consequently, it is possible to use the whole benefits of BIM, for instance analysis of thermal comfort, sustainability of materials and systems, cost, and schedule.

Another aspect that facilitates the use of BIM is the presence of collaboration throughout the process. This indicates that the team can work together on the same virtual model, in a collaborative environment.

DBB is the least appropriate for integration, and it is very difficult to benefit from the use of BIM, especially if its usage and handing over of model aren't in the contracts. And since each participant is responsible only for his own activity, it is extremely difficult to establish a collaborative environment.

DB and CMAR have features that enable collaboration and promote integration, e.g. the early participation of the contractor. However, integration does not span through the whole process, since collaboration may occur only in some activities and the subcontractor is not presented in the concept and design stages.

Consequently, the main decisions of a project are made similarly on DBB, DB, and CMAR project delivery methods. The end of the decisions of what, how and who advances to the construction stage, because the subcontractor is the last participant involved in the process. This agent might bring issues or better solutions not considered in during the design stage. For that reason, the design cannot be considered finished until the participation of all agents.

The differences regarding integrated project delivery methods - PP, PA, ECI, and IPD - relates to the degree of collaboration during the concept stage. It is possible to identify that the involvement of the agency from the beginning of the process greatly reduces the possibility of rework. This feature indicates that IPD is the contracting type that gives better support for integration and consequently facilitates the use of the whole features of BIM.

This research contributes to both theoretic and practical approaches to the construction industry by clarifying the characteristics of contracting types that will establish the project delivery method. The visual analysis of the process allows a better understanding of the similarities and differences among methods and can be applied to any existing or proposed contract scheme.

The integration of the process may be achieved by different instruments, and the integration may be applied to the whole process or to specific stages. When it is decided to use BIM in a construction process, it is fundamental to consider which type of contract will be used. This decision will influence the organization of the project delivery method and the possibilities for improvement of the BIM use.
5 


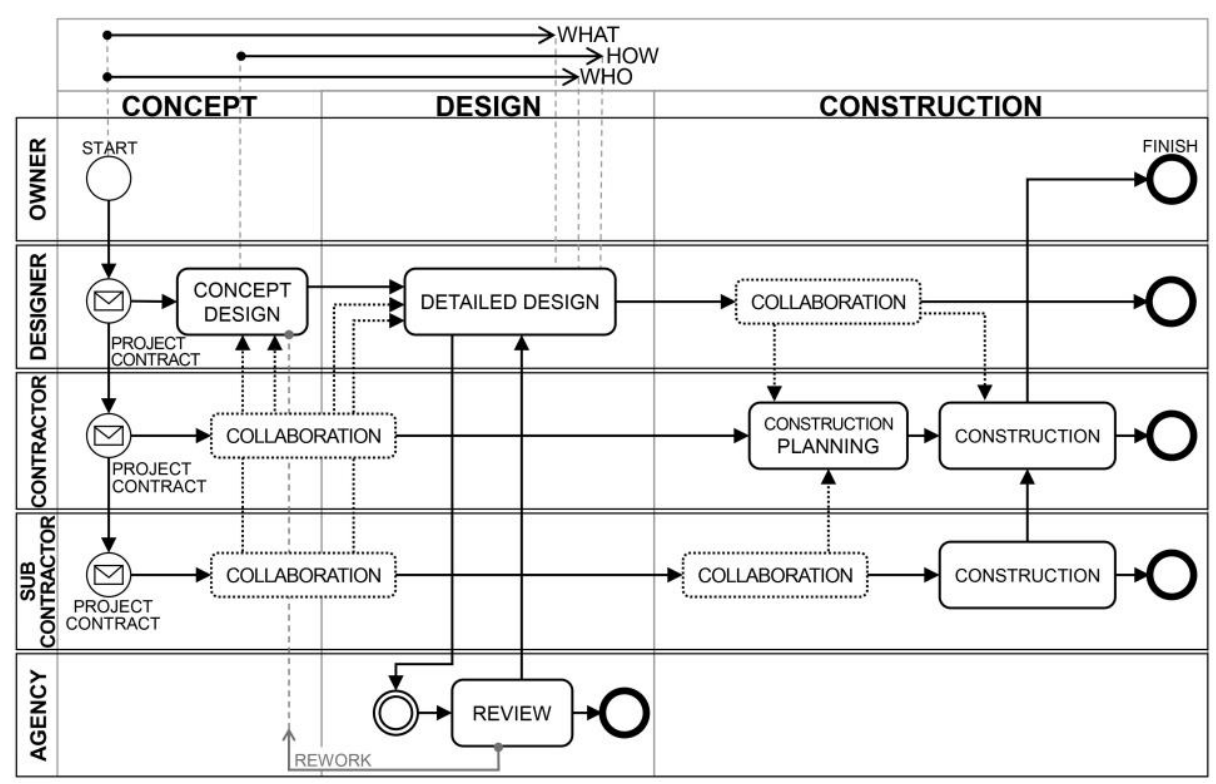

Figure 9: Diagram for Project Partnering (PP) and Project Alliancing (PA).

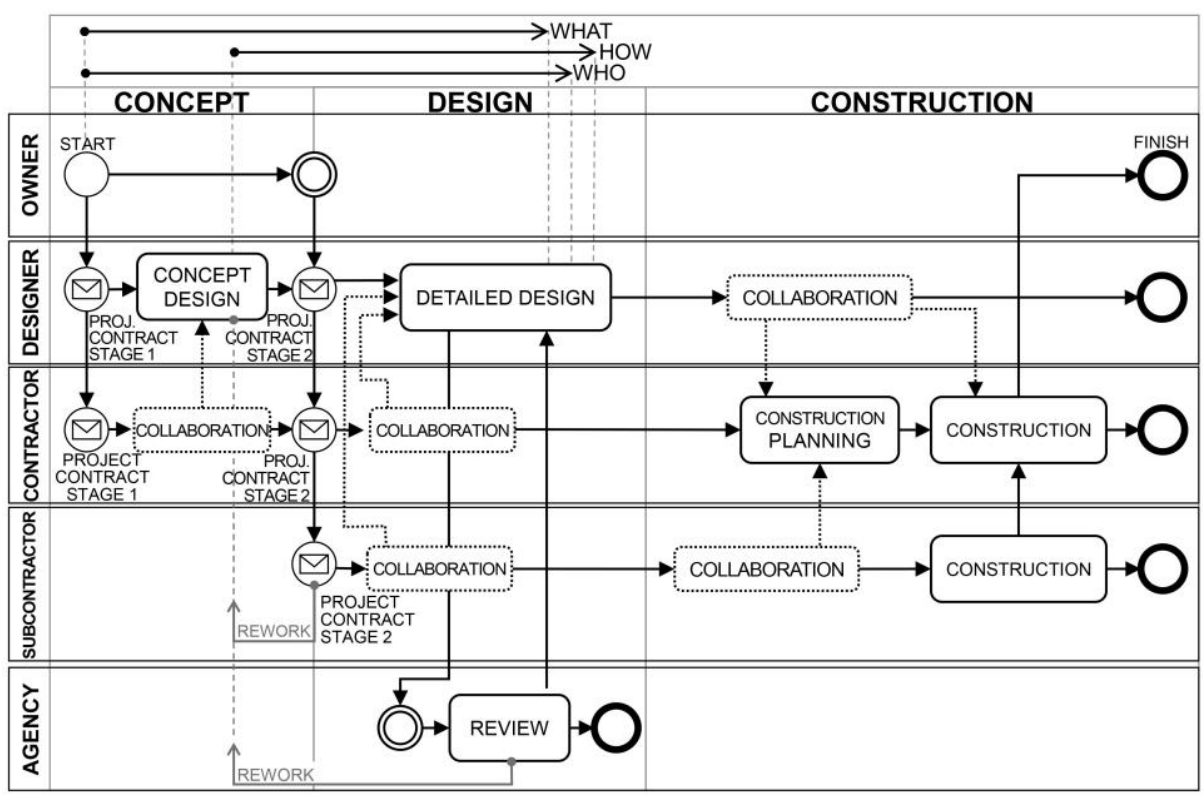

Figure 10: Diagram for Early Contractor Involvement (ECI).

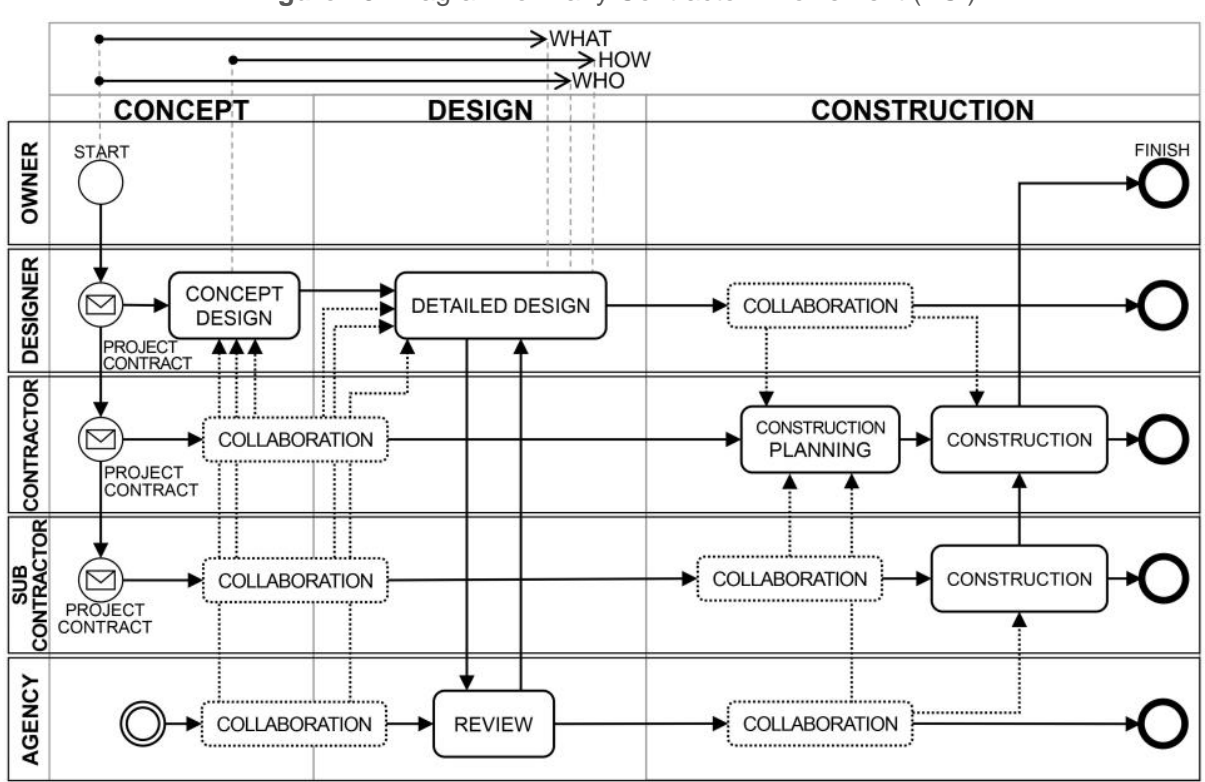

Figure 11: Diagram for Integrated Project Delivery (IPD).

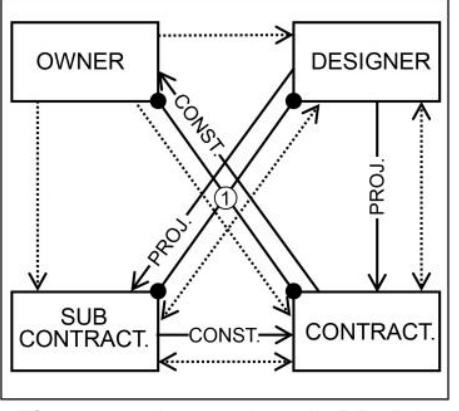

Figure 12: Interactions in PP, PA, $\mathrm{ECl}$, and IPD. 


\section{ACKNOWLEDGMENTS}

We thank CAPES for financial support for this research.

\section{REFERENCES}

American Institute of Architects. (2014). Integrated Project Delivery - An updated working definition - Version 3. Sacramento, CA: AIA California Council.

Eastman, C., et al. (2011). BIM Handbook: A Guide to Building Information Modeling for Owners, Managers, Designer, Engineers and Contractors (2nd ed.). Hoboken: John Wiley \& Sons, Inc.

Egan, J. (2002). Accelerating change. London: Rethinking Construction, Strategic Forum for Construction. London: Construction Industry Council.

El Asmar, M., Hanna, A. S.; Loh, W. (2015). Evaluating Integrated Project Delivery using the Project Quarterback Rating. Journal of Construction Engineering and Management, 142. doi: 10.1061/(ASCE)CO.1943-7862.0001015

Harper, C. M., Molenaar, K. R.; Cannon, J. P. (2016). Measuring Constructs of Relational Contracting in Construction Projects: The Owner's Perspective. Journal of Construction Engineering and Management, 142, 1087-1098. doi: 10.1061/(ASCE)CO.1943-7862.0001169

Lahdenperä, P. (2012). Making sense of the multi-party contractual arrangements of project partnering, project alliancing and integrated project delivery. Construction Management and Economics, 30, 57-79. doi:10.1080/01446193.2011.648947
Matthews, O., Howell, G. A. (2005). Integrated Project Delivery an Example of Relational Contracting. Lean Construction Journal, 2.

Miettinen, R., Paavola, S. (2014). Beyond the BIM utopia: approaches to the development and implementation of building information modeling. Automation in Construction, 43, 84-91. https://doi.org/10.1016/j.autcon.2014.03.009.

Molenaar, K., Sobin, N. (2009). Sustainable, High Performance Projects and Project Delivery Methods: A State-of-Practice Report. Vancouver, WA: Charles Pankow Foundation.

Mosey, D. (2009). Early Contractor Involvement in Building Procurement: Contracts, Partnering and Project Management. Oxford: John Wiley \& Sons, Ltd.

Nam, C. H., Tatum, C. B. (1992). Noncontractual Methods of Integration on Construction Projects. Journal of Construction Engineering and Management, 118, 385-398.

Object Management Group. (2011). Business Process Model and Notation (BPMN) - Version 2.0. Retrieved from http://www.omg.org/spec/BPMN/2.0/

Rahman, M. M., Kumaraswamy, M. M. (2005). Relational Selection for Collaborative Working Arrangements. Journal of Construction Engineering and Management, 131. doi: 10.1061/(ASCE)0733-9364(2005)131:10(1087)

Scheepbouwer, E., Humphries, A. B. (2011). Transition in Adopting Project Delivery Method with Early Contractor Involvement. Journal of the Transportation Research Board, 2228, 44-50. doi:10.3141/2228-06 